\title{
As visões sobre a ciência e sobre a realidade nos enunciados de Richard P. Feynman: Uma análise metalinguística de alguns de seus textos didáticos e de divulgação científica
}

The views on science and reality in Richard P. Feynman's statements: A metalinguistic analysis of some of his textbooks and scientific dissemination

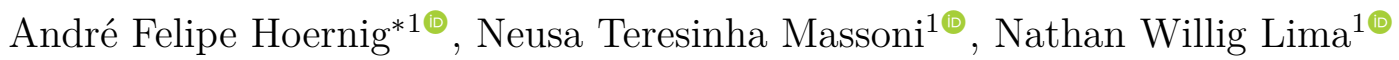 \\ ${ }^{1}$ Universidade Federal do Rio Grande do Sul, Programa de Pós-Graduação em Ensino de Física, Porto Alegre, RS, Brasil.
}

Recebido em 13 de Janeiro de 2020. Revisado em 07 de Abril de 2020. Aceito em 07 de Abril de 2020.

\begin{abstract}
Este trabalho faz uma incursão através de algumas obras de Richard Feynman, com uma análise metalinguística dos enunciados de Física Quântica presentes na obra Lições de Física, bem como nas obras QED: a estranha teoria da luz e da matéria e Os melhores textos de Richard P. Feynman. Investigamos como que o tema, a estrutura composicional e a escolha lexical expressam a enunciação de visões epistemológicas e ontológicas subjacentes à apresentação do conteúdo físico. Nossos resultados mostram que o jovem cientista apresenta o conteúdo físico alinhado axiologicamente com a Interpretação de Copenhague, adquirindo, em certos momentos, um viés positivista. Contudo, nas obras posteriores às Lições de Física, Feynman assume uma postura de maior preocupação com a divulgação científica. A direcionalidade, o projeto de fala e a intencionalidade de seus enunciados tornam seus textos recheados de visões complexas sobre a natureza das teorias científicas. Conclui-se que o conjunto de obras de Feynman apresenta uma profícua contribuição ao ensino de Física e à divulgação da ciência, adotando diferentes vozes acerca da natureza da realidade e da ciência, sendo responsável ao período sociopolítico das diferentes enunciações, o que é um exemplo rico da não-neutralidade científica e pedagógica.
\end{abstract}

Palavras-chave: Bakhtin, Epistemologia, Física Quântica, Eletrodinâmica Quântica.

This work makes an inroad through some works of Richard Feynman, with a metalinguistic analysis of Quantum Physics statements in the Lectures on Physics, as well as in QED: The Strange Theory of Light and Matter and The Pleasure of Finding Things Out: The Best Short Works of Richard P. Feynman. We investigate how the theme, compositional structure, and lexical choices express the enunciation of epistemological and ontological visions underlying the presentation of physical content. Our results show that the young scientist presents the physical content axiologically aligned with the Copenhagen Interpretation, acquiring at times a positivist bias. However, in later post-Lectures on Physics works, Feynman takes a stance of greater concern with scientific dissemination. The directionality, the speech scheme, and the intentionality of his utterances make his texts full of complex views on the nature of scientific theories. It is concluded that Feynman's set of works makes a useful contribution to the teaching of physics and the dissemination of science, adopting different voices about the nature of reality and science, being responsible for the sociopolitical period of the different utterances, which is a rich example of scientific and pedagogical non-neutrality.

Keywords: Bakhtin, Epistemology, Quantum Physics, Quantum Electrodynamics.

\section{Introdução}

Apesar de a comunidade de Pesquisa em ensino de Física apontar há décadas a necessidade de inserção de discussão de visões epistemológicas na sala de aula [1], isso não é um consenso para a comunidade de físicos ou mesmo para a comunidade de educadores [2]. São atribuídas a Richard P. Feynman, prêmio Nobel de Física em 1965 e um dos principais pesquisadores na história da Física Quântica, afirmações que diminuem a importância do estudo sobre a natureza da ciência [3]. Entretanto, devese ter em mente que em toda apresentação de tópicos

*Endereço de correspondência: andre.hoernig@gmail.com de Física, explícita ou implicitamente, apresenta-se uma definição do que é ciência, qual sua validade, qual seu objetivo, como se dá a sua prática [4]. É possível, portanto, questionar se a obra didática sobre Física de Feynman reflete as visões epistemológicas que lhe são atribuídas, ou se outras podem aparecer quando se analisa seus enunciados. Mais especificamente, considerando sua contribuição à Física Quântica e o papel emblemático de sua obra no Ensino de Física ${ }^{1}$ temos o objetivo, neste trabalho, de

\footnotetext{
${ }^{1}$ Lições de Física são um conjunto de lições, por sua vez, constituem importante subsídio e material de apoio para os alunos de física, sendo parte da literatura básica de cadeiras importantes como Teoria Eletromagnética e frequente literatura complementar de cursos de física moderna. É interessante ressaltar que as lições foram
} 
analisar a abordagem epistemológica e ontológica dada à natureza da luz por Richard P. Feynman, contida nos capítulos iniciais do terceiro volume da obra "Lições de Física" (nos quais a Física Quântica é introduzida de forma sistemática), além de uma comparação com a visão do cientista em obras mais recentes; QED: a estranha teoria da luz e da matéria, originalmente publicado em 1985, e Os Melhores Textos de Richard P. Feynman, que se constitui de uma coleção de palestras e entrevistas ministradas ao longo dos anos, publicado postumamente em 1999.

\section{Marco Teórico}

Esse trabalho apresenta uma análise qualitativa, a dizer, uma interpretação metalinguística fundamentada na Filosofia da Linguagem de Mikhail Bakhtin [5] e sua Teoria do Enunciado Concreto [6], que se caracteriza por analisar os processos de comunicação discursiva em sua ocorrência concreta [4]. Bakhtin [5] entende que os enunciados refletem as condições específicas e as finalidades de cada campo da comunicação social. Segundo essa visão, todo enunciado é fruto de uma interação social, na qual toda expressão linguística é voltada ao outro, mesmo que esse outro esteja fisicamente ausente. "Ela (a linguagem) é um produto da vida social, a qual não é fixa nem petrificada: a linguagem encontra-se em um perpétuo devir e seu desenvolvimento segue a evolução da vida social" (1981, p. 1) [7]. Em dadas situações, como em um monólogo, embora não observemos indivíduos respondentes, há um processo comunicativo que se dá na forma de um diálogo, uma vez que cada ouvinte tem uma reação que resulta em uma resposta, ainda que essa seja expressa apenas mentalmente, sendo essa possiblidade de elaboração de respostas a enunciados conhecida como responsabilidad $\AA^{2}[11]$. Ademais, o enunciado dialoga com enunciados anteriores, seja no contexto imediato (no caso de um diálogo cotidiano) ou no campo da cultura, como no caso de livros. Nesse sentido, o enunciado é repleto de tonalidades dialógicas, ele nunca é a expressão pura de um único locutor, "porque a nossa própria ideia nasce e se forma no processo de interação e luta com os pensamentos dos outros" (2016, p. 59) [5]. Por essa razão, Bakhtin descreve o enunciado como representado por ecos das alternâncias dos sujeitos do discurso, sendo ele um fenômeno muito complexo e multiplanar. Ao dialogar com os enunciados dos outros, pode-se dizer que

confeccionadas com base em uma série de conferências ministradas no Caltech (California Institute of Technology), no período de 1962-1964, com objetivo de animar alunos desmotivados nos estudos de física. Tal movimento era parte de uma tendência pedagógica, após o lançamento do satélite Sputnik pela União Soviética em 1957 [8]. O objetivo desse movimento era motivar os alunos a seguirem carreiras científicas e persistirem nela. Conforme aponta David Kaiser [9,10], nesse período, o ensino deveria ter um caráter instrumentalista, sem se preocupar com questões filosóficas, com o objetivo de formar rapidamente engenheiros e cientistas.

2 O termo em inglês é answerability. Adotamos o termo "responsabilidade", embora alguns tradutores empreguem, também, o termo "responsividade".
Os enunciados não são indiferentes entre si nem bastam cada um a si mesmos; uns conhecem os outros e se refletem mutuamente uns nos outros. Esses reflexos mútuos lhes determinam o caráter. Todo enunciado é pleno de ecos e ressonâncias de outros enunciados com os quais está ligado pela identidade da esfera da comunicação discursiva. Todo enunciado deve ser visto antes de tudo como uma resposta aos enunciados precedentes de um determinado campo (aqui concebemos a palavra "resposta" no sentido mais amplo): ela os rejeita, confirma, completa, baseia-se neles, subentende-os como conhecidos, de certo modo os leva em conta" [5, p. 57].

Ao longo do enunciado, ademais, pode-se identificar a presença de vozes, isto é, consciências falantes, que expressam a visão de mundo de um determinado grupo social [12]. No caso do presente trabalho, identificamos as diferentes visões ontológicas e epistemológicas como vozes que são veiculadas nos enunciados de Feynman, as quais não aparecem de forma neutra, e respondem ao projeto de fala do locutor e ao contexto extra verbal.

O trabalho da Interpretação Metalinguística consiste, assim, em delimitar os enunciados concretos (entendidos como a unidade real e concreta da comunicação verbal), reconhecer suas características constitutivas e indissociáveis (estrutura composicional, tema e estilo) [6] e interpretar o sentido do enunciado à luz do contexto extra verbal (o qual pode ser entendido como o contexto imediato, o contexto sociocultural ou mesmo um amplo contexto do grande diálogo da cultura) [11].

\section{Método}

A sequência de passos seguidos na análise é baseada na proposta de Veneu, Ferraz e Rezende [11]. A primeira etapa consiste em selecionar os enunciados que são o objeto de estudo da Física Quântica. Um enunciado é uma unidade de comunicação real e pode ser reconhecido através das seguintes características: conclusibilidade, projeto de fala do locutor, possibilidade de resposta, formas de acabamento típicas do gênero do discurso em questão. Embora um romance inteiro possa ser considerado um enunciado, no caso de livros didáticos, é possível que um capítulo ou seção específica apresente as características necessárias para caracterizá-lo como enunciado [4]. Com base nisso, os enunciados escolhidos como objeto de estudo são os capítulos 1 e 2 do terceiro volume do livro Lições de Fúsica [13]. Com isso, faz-se uma leitura genérica do enunciado, na qual mapeamos o tema dos enunciados escolhidos bem como sua estrutura composicional (discutidos na seção 4.1). A terceira etapa consiste em um mapeamento do contexto extra verbal - no caso do presente artigo, o contexto extra verbal engloba não só a biografia de Feynman, a situação sociopolítica em que o enunciado é veiculado, bem como as possíveis escolas de Interpretação da Física Quântica e Eletrodinâmica Quântica e suas visões ontológicas e epistemológicas (o 
que configuraria o diálogo no grande tempo da cultura). A última etapa da análise das Lições consiste em interpretar os enunciados à luz dos conceitos da Filosofia da Linguagem. Por fim, os resultados levantados para a análise desta primeira obra são comparados ao posicionamento presente em obras posteriores, seguindo-se de uma reflexão acerca da visão geral sobre Ciência e Epistemologia da Ciência imbricadas nas declarações e expressões verbais de Richard Feynman.

Apresentaremos os resultados, discutindo, primeiramente, o que pode ser identificado com uma primeira leitura (seção 4.1) e, na sequência, a interpretação metalinguística à luz do contexto extra verbal (seção 4.2). Por fim, discutimos as vozes presentes em textos posteriores de Feynman em diálogo com o que é apresentado nas Lições (seção 4.3 e 4.4).

\section{Resultados}

\subsection{Primeira Leitura dos Enunciados: a Introdução da Física Quântica na Lições de Física}

Para se introduzir a física quântica, identificam-se, na literatura, três principais caminhos [14]: o mais comum é trazido pela escola espanhola, segundo a qual introduzse a física quântica a partir das limitações dos modelos clássicos. Lima et al. [4] mostram que todos os livros do Plano Nacional do Livro Didático (PNLD) de 2015 adotaram essa abordagem. A escola alemã, no entanto, aborda a possibilidade desta introdução ser feita a partir da apresentação direta do formalismo quântico, buscando evitar quaisquer relações e analogias com a teoria clássica. Por fim, uma terceira forma é a abordagem americana, que se dá através da apresentação de alguns tópicos introdutórios e genéricos para familiarizar os alunos.

Através do estudo das Lições de Física, identificamos que Feynman parece seguir uma abordagem própria, nãohistórica ${ }^{3}$ mas, também, sem recair em uma abordagem puramente postulacional e abstrata. O formalismo de Dirac, por exemplo, é apresentado ao leitor apenas no terceiro capítulo. Um ponto importante a ser ressaltado é que, enquanto a abordagem espanhola segue a história do fóton, Feynman não discute a natureza da luz; mas parte diretamente para o estudo de elétrons. Com isso, ele evita passar por interpretações corpusculares realistas como é feito comumente em livros de ensino superior [4], interpretações estas que assumem uma perspectiva epistemológica realista e ontológica corpuscular para o fóton e, segundo Lima et al. [4], essa era a visão original de Einstein em 1905 no famoso artigo Sobre um Ponto de Vista Heurístico sobre Emissão e Transformação da Luz. Um contraponto possível para uma interpretação corpuscular realista para o fóton seria a interpretação realista ondulatória, que, ainda defendendo o fóton como

\footnotetext{
3 No capítulo inicial da obra temos apenas os nomes de Newton, Schroedinger, Born e Heisenberg citados, uma vez para os três primeiros e cinco vezes para este último. A quantidade de vezes que cita Heisenberg pode ser um indicativo do alinhamento do autor com a Escola de Copenhague.
}

entidade independente da interação, e, portanto, realista, explica os fenômenos com base na noção de pacotes de onda. Pode haver, contudo, diversas interpretações, como salienta Pessoa Jr. [15], que diferem quanto ao posicionamento epistemológico (realismo e antirrealismo), ou quanto ao posicionamento ontológico (onda e partícula). O primeiro elemento dos enunciados concretos de que podemos nos valer é a estrutura composicional do texto. No Quadro 1 apresentamos os subtítulos do capítulo.

Todo o capítulo traz uma abordagem sobre a dualidade onda-partícula, com diversos experimentos pensados e idealizados para buscar entender a natureza dual da matéria. Diferentemente de outras obras, a "Lições de Física" nos proporciona com uma abordagem verdadeiramente dualista, no sentido dado por Martins e Rosa [16], não trazendo uma visão filosoficamente inconsistente como acontece em livros introdutórios de nível superior, em que "os autores alternam a veiculação de interpretações da FQ sem nenhuma discussão profunda sobre o assunto" (2017, p. 6) [4]. Além da estrutura do Capítulo 1, apresentamos, também, a estrutura do Capítulo 2 para fornecer mais subsídios para a presente discussão, conforme esquematizado no Quadro 2.

A última seção do Capítulo 2, traz uma discussão filosófica da Física Quântica, o que indica que, mesmo que o físico privilegie a abordagem matemática ou fenomenológica, a Física Quântica demanda uma discussão de cunho filosófico. Ainda que essa só apareça explicitamente na seção 2-6, ao falar dos experimentos e do formalismo, Feynman não pode se abster de veicular uma visão ontológica e epistemológica. Isso será apresentado na próxima seção.

\subsection{Análise da Obra Lições de Física}

Para compreender as vozes ontológicas e epistemológicas presentes nos enunciados do objeto de estudo, podemos

Quadro 1: Sobre a estrutura do primeiro capítulo.

\begin{tabular}{lc}
\hline \multicolumn{2}{c}{ Capítulo 1: Comportamento Quântico } \\
\hline Seção & Título \\
\hline $1-1$ & Mecânica atômica \\
\hline $1-2$ & Uma experiência com projéteis \\
\hline $1-3$ & Uma experiência com ondas \\
\hline $1-4$ & Uma experiência com elétrons \\
\hline $1-5$ & A interferência de ondas de elétrons \\
\hline $1-6$ & Observando os elétrons \\
\hline $1-7$ & Primeiros princípios da mecânica quântica \\
\hline $1-8$ & O Princípio da Incerteza \\
\hline
\end{tabular}

Quadro 2: Sobre a estrutura do segundo capítulo. Capítulo 2: A relação entre os Pontos de Vista Ondulatório e Corpuscular

\begin{tabular}{lc}
\hline Seção & Título \\
\hline $2-1$ & Amplitudes de Ondas de Probabilidade \\
\hline $2-2$ & Medidas de Posição e Momento \\
\hline $2-3$ & Difração em um cristal \\
\hline $2-4$ & O tamanho de um átomo \\
\hline $2-5$ & Níveis de Energia \\
\hline $2-6$ & Implicações Filosóficas \\
\hline
\end{tabular}


nos valer de elementos do prefácio do terceiro volume, que nos fornece alguns indicativos sobre a visão que é expressa na obra, uma vez que atribui importância ao ensino mais individualizado, notam-se algumas semelhanças com o que caracteriza uma visão não tradicional de ensino:

Acredito, porém, que não há solução para esse problema de ordem educacional, a não ser abrir os olhos para o fato de que o ensino mais adequado só poderá ser levado a cabo nas situações em que houver um relacionamento pessoal direto entre o aluno e bom professor - situações nas quais o estudante discuta as ideias, reflita e converse sobre elas [13, p. 5].

A visão de ensino exposta por Feynman parece carregar a ideia de que o aprendizado da ciência não acontece com uma simples memorização (ou recepção de conhecimentos, como se o aluno fosse uma tábula rasa). Sua concepção de construção do conhecimento pelo aluno, se opondo à redução do aprendizado à memorização, é corroborada pelos relatos da visita de Richard Feynman ao Brasil, quando se mostrou insatisfeito com a "aprendizagem mecânica" [17], no sentido em que os livros em português enfatizavam um aprendizado por memorização e não o desenvolvimento do raciocínio lógico.

Ainda no prefácio, podemos encontrar uma justificativa do porquê de Feynman não seguir à risca uma ordem cronológica em suas aulas, uma vez que afirma: " Além disso, não via o menor motivo para organizar as conferências dentro de uma ordem definida, no sentido de não poder mencionar determinado tópico até que estivesse pronto para discuti-lo em detalhe." [13, p.3]. Sendo assim, não parece haver preocupação em expressar linearidade na ciência, mas parece admitir que conceitos científicos podem ser interpretados e reinterpretados em diferentes épocas e contextos. O primeiro cientista citado já no capítulo primeiro, "Comportamento Quântico", é Newton:

Newton pensava que a luz fosse composta de partículas, mas então descobrimos que ela se comporta como uma onda. Depois, entretanto (no começo do século XX), descobrimos que a luz às vezes se comporta como uma partícula. Historicamente, pensávamos que o elétron, por exemplo, se comportasse como uma partícula e então descobrimos que em muitos aspectos ele se comporta como onda. Agora desistimos. Nós dizemos: "É como nenhum dos dois. [13, p.1, grifo nosso].

As expressões destacadas em negrito parecem indicar uma escolha lexical associada à visão positivista, pois trazem a ideia de "descoberta", como se a realidade fosse simplesmente desvelada aos olhos do cientista tal como ela é. O positivismo parece ser reforçado quando o autor se refere à dualidade onda partícula:

Entretanto, temos um pouco de sorte - elétrons se comportam como a luz. O compor- tamento dos objetos atômicos (elétrons, prótons, nêutrons, fótons e assim por diante) é o mesmo para todos, todos são "ondas de partículas" ou como quer que você queira chamá-los. [13, p. 1, grifo nosso].

Por um lado, a expressão "como quer que você queira chamá-los" - "Você pode chamar do que quiser, isso não é importante.", poderia ser interpretada como um descaso com relação à discussão filosófica; de outro lado, pode Feynman estar tentado passar uma ideia do quão movediço é o terreno quando se abandona o mundo clássico e se adentra, tentando compreender o mundo quântico, no sentido de que seria importante explicar aos estudantes que são introduzidos à Física Quântica que estes objetos - os "entes quânticos" e seu comportamento em nada se assemelham aos do mundo cotidiano, e é nesse sentido que podemos lhes dar "qualquer nome" ou "chamá-los do que quiser", como diz Feynman.

Feynman propõe reflexões sobre o comportamento de elétrons no experimento de dupla fenda, reflexões estas através de experimentos pensados: "Estamos fazendo um "experimento na mente", que escolhemos porque é fácil de pensar nele" [13, p.1-5]. A expressão "porque é fácil de pensar nele" exemplifica a proposta pedagógica pragmática e instrumentalista de Feynman, levando os alunos, rapidamente, para o coração da Teoria Quântica, sem passar por reflexões históricas e epistemológicas. Tal estilo de abordagem, além de poder refletir algum estilo pessoal do cientista, é, também, resultado do contexto extra verbal no qual o enunciado é proferido. As Lições acontecem em período de Guerra Fria, após o lançamento do satélite Sputnik, quando havia uma forte preocupação com a formação de cientistas e engenheiros [8] - não havia tempo para discutir filosofia da ciência. Era necessário viabilizar que os alunos, rapidamente, dominassem os conceitos fundamentais da Física Contemporânea $[9,10]$. Feynman, que, anteriormente, havia participado ativamente do Projeto Manhattan, parecia comprometido com os interesses sociopolíticos de sua época.

Ainda sobre o capítulo um, na série de experimentos pensados, o autor apresenta algumas conclusões sobre a probabilidade de detecção em um anteparo no experimento de dupla fenda para elétrons. O que segue é uma discussão sobre as probabilidades de detecção em um anteparo, no qual destaca a importância matemática pela relação com um experimento para ondas:

$\mathrm{O}$ resultado para $\mathrm{P}_{12}$, obtido quando os dois orifícios estão abertos, claramente não é a soma das probabilidades de cada orifício separadamente, $\mathrm{P}_{1}$ e $\mathrm{P}_{2}$. Por analogia com nossa experiência com ondas, podemos dizer: "existe interferência". [...] O que se passa no anteparo pode ser descrito por dois números complexos que chamaremos de $\phi_{1}$ e $\phi_{2}$ (e que não função de $\mathrm{x}$ ). $\mathrm{O}$ valor absoluto quadrático quando apenas o orifício 1 está aberto. $\mathrm{Ou}$ seja, $P_{1}=\left|\phi_{1}\right|^{2} \mathrm{O}$ efeito com apenas o orifício 2 aberto é dado por $\phi_{2}$ da mesma forma. $\mathrm{Ou}$ 
seja, $P_{2}=|\phi|^{2}$. E o efeito combinado dos dois orifícios é $P_{12}=\left|\phi_{1}+\phi_{2}\right|^{2}$. A matemática é a mesma para o caso de ondas! [13, p. 1-6, grifo do autor].

Nesse trecho, de uma forma geral, pode-se dizer que Feynman se limita a descrever a relação entre o formalismo matemático da Teoria Quântica e os resultados experimentais, sem se comprometer com nenhuma interpretação específica. No trecho subsequente, entretanto, encontramos a apresentação de uma interpretação filosófica da teoria:

Concluímos então o seguinte: os elétrons chegam em unidades, como as partículas, e a probabilidade de chegada dessas unidades é distribuída como a distribuição de intensidade de uma onda. É nesse sentido que os elétrons se comportam "algumas vezes como partícula e outras como onda." [13, p. 1-6, grifo nosso].

Essa conclusão é interessante no momento em que nos mostra que o elétron se comporta ora como partícula, ora como onda, mas nunca como ambos. Essa afirmação é um dos pilares da interpretação da complementariedade, que exprime a noção de Bohr de que onda e partícula são aspectos mutuamente excludentes, mas complementares, da natureza. Ou seja, para representar um objeto quântico como um elétron, ou um fóton, podemos encará-lo ou como partícula, para certas situações experimentais, ou como onda, para outras situações, "mas nunca como ambos ao mesmo tempo" (2003, p. 18) [15].

O próximo experimento pensado que Feynman propõe leva o leitor imediatamente ao coração da Física Quântica: a noção de dualidade onda-partícula. Pensando em termos de luz, sabemos que é detectada em termos de fótons individuais, o que nos leva a uma tendência de afirmar que esses fótons mantêm sua individualidade enquanto não são observados. Tal intuição tende a ser ainda mais forte no caso de elétrons, o que se justifica por eles satisfazerem à conservação de número fermiônic ${ }^{4}$. Mas "se seguirmos essa intuição, teremos que admitir que o elétron passou ou pela fenda A ou pela fenda B." (2003, p. 155) [15]. Teríamos alguma forma de verificar essa suposição? Feynman propôs que tentássemos medir a posição do elétron, tentar "olhar os elétrons", quando eles passassem pelas fendas, por meio de uma fonte de luz colocada entre as fendas (na verdade tal experimento é análogo ao que teria sido desenvolvido por Möllenstedt \& Dücker em 1954). O que se observa é o seguinte:

Ou seja, embora tenhamos sucedido em observar por qual orifício passam os elétrons, já não obtemos nossa curva de interferência $P_{12}$,

\footnotetext{
${ }^{4}$ Respeitar o número fermiônico significa respeitar o princípio de exclusão de Pauli, que afirma que dois entes de spin semi-inteiro, os férmions, não podem ocupar simultaneamente o mesmo estado quântico. Os elétrons são férmions, o que faz com que a intuição de que eles mantenham sua individualidade seja ainda maior que para os fótons, bósons que não seguem o princípio de exclusão.
}

mas sim uma nova $P_{12}^{\prime}$, que não apresenta interferência! Se apagarmos a luz, $P_{12}$ será restaurada. [13, p. 1-12].

Com isso, Feynman tenta esclarecer que no momento em que podemos afirmar qual caminho o elétron tomou, destrói-se o padrão de interferência e nosso elétron passa a ser descrito como partícula. Desta forma, ele reforça o estranho comportamento dual do elétron como ondapartícula (como ente quântico, um elétron pode passar pelos dois orifícios, o que não acontece com uma pessoa diante de duas portas no mundo clássico, por exemplo). No seguinte trecho, Feynman, após se alinhar com a visão de Copenhague 5 no restante do texto, apresenta uma menção a uma interpretação que defende a existência de variáveis ocultas:

Faremos agora algumas considerações sobre sugestões que foram feitas para tentar evitar a descrição que demos: "talvez o elétron tenha algum tipo de trabalho interno - algumas variáveis internas - que ainda não sabemos. Talvez seja por isso que não conseguimos predizer o que vai acontecer. Se pudéssemos olhar mais de perto, seríamos capazes de predizer aonde ele vai". Até onde sabemos isso é impossível. [13, p. 1-17, grifo nosso].

\footnotetext{
5 A interpretação de Copenhague é devida essencialmente à Bohr, Heisenberg e Pauli, quando estes discutiam alguns aspectos filosóficos da Mecânica Quântica, com essas discussões ocorrendo geralmente no laboratório de Bohr, em Copenhague. É uma das mais antigas das numerosas interpretações da Mecânica Quântica, segundo a qual, em mecânica quântica, os sistemas físicos não têm propriedades bem definidas antes de uma medição, mas sim uma distribuição de probabilidades, na chamada função de probabilidade. Heisenberg [18, p.21] esclarece que a função de probabilidade "contem afirmações sobre as possibilidades ou melhor tendências ('potentia' na filosofia aristotélica), e essas afirmações são completamente objetivas, elas não dependem de nenhum observador". Desta forma, uma primeira tese dessa interpretação é que as previsões da Mecânica Quântica são probabilísticas e irredutíveis, refletindo as tendências do sistema físico em termos de probabilidades. Tem-se também a defesa de que a base para a construção de uma teoria são os resultados dos processos de medida, de forma que não há sentido nas discussões que não se relacionam com as medições. Segundo Heisenberg [18], a pergunta, "Mas o que acontece 'realmente' em um evento atômico?", no sentido de "O que acontece entre duas medições?", é uma pergunta para a qual não há uma resposta objetiva viável. Ele esclarece que "qualquer tentativa de achar essa descrição levaria a contradições, isso deve significar que o termo 'acontecer' está restrito à observação". [18, p.20]. Por fim, há ainda grande importância dada ao processo de observação, uma vez que "a observação em si muda a função de probabilidade descontinuamente, ela seleciona de todos os possíveis eventos aquele que verdadeiramente acontece. Uma vez que por meio da observação nosso conhecimento do Sistema mudou descontinuamente, sua representação matemática também foi submetida a uma mudança e nós falamos de um "salto quântico" [18, p.22]. Desta forma, tem-se a terceira importante tese da interpretação de Copenhague, que o ato de observar provoca o que é conhecido como colapso da função de onda, o que significa que, apesar das muitas possibilidades expressas na função de probabilidade, apenas uma é selecionada, quando é feito o ato de medição, e a função de onda modifica-se instantaneamente para refletir essa escolha. Algumas escolhas lexicais de Feynman em sua obra remetem às três teses da interpretação de Copenhague.
} 
Nesse trecho está subjacente, em nossa interpretação, uma visão epistemológica bastante clara e atual, embora implícita: a ideia de que o conhecimento científico, especialmente na ciência de fronteira, é uma construção inacabada; quando afirma "Até onde sabemos, isso é impossivel,", ele parece deixar em aberto a possibilidade de que teorias/descobertas/novos achados podem vir a revelar algo diferente do que hoje se sabe.

No capítulo dois, "Amplitudes de Ondas de Probabilidades", nas seções que nos propomos analisar temos uma discussão sobre o princípio de incerteza mais aprofundada. Para a relação entre a incerteza no momentum e na posição, temos uma interessante conclusão do autor, ao afirmar que:

[...] se refere à previsão de uma situação, e não a comentários sobre seu passado. Nada vale dizer "sabia o momento antes de passar pelo orifício e agora sei sua posição", porque agora o conhecimento do momento foi perdido. O fato de que ele passou pelo orifício já não permite predizer o momento vertical. Estamos falando sobre uma teoria preditiva e não apenas de medidas depois do fato. Devemos, portanto, falar do que podemos prever 13 , p. 2-3, grifo do autor].

Para esta interpretação é atribuída realidade apenas para o que é observado, a rigor não faz sentido perguntar qual era a posição de um objeto quântico antes da medição. O que, novamente, está alinhado com a Interpretação de Copenhague.

Finalizando o capítulo segundo, a seção 2-6 é rica em discussões filosóficas, o que fica claro quando é levantada a pergunta: "O problema foi colocado: se uma árvore cai na floresta e não há alguém observando, ela faz barulho?" (2010, p. 2-8) [13]. Aqui ele parece não adotar uma visão positivista; para um positivista uma resposta plausível seria que essa pergunta não faz sentido, algo que se alinha com a visão da escola de Copenhague. Mas na verdade temos uma surpresa, pois levanta uma discussão um tanto realista:

Uma árvore de verdade caindo numa floresta de verdade faz barulho, é claro, mesmo que ninguém esteja lá. Mesmo que ninguém esteja presente outros indícios existem. O som balança algumas folhas e, se formos cuidadosos o suficiente, poderemos encontrar em algum lugar que um espinho encostou numa folha e deixou um arranhão que não poderia ser explicado a menos que assumíssemos que a folha estava vibrando. De alguma forma teríamos que admitir que houve um som. [13, p. 2-8, grifo do autor].

Ficamos aqui com a sensação de que Feynman assume uma visão realista, isto é, a realidade está lá independente de nós, abandonando a ideia de que só é possível falar daquilo que podemos medir. Se assumirmos uma posição crítica, podemos dizer que, na verdade não há nenhuma surpresa nesta afirmação e devemos imaginar que o autor assim se posiciona para manter consistência na sua posição. Feynman conhece e não ignora as outras interpretações da física quântica para a dualidade onda-partícula, apenas prefere a interpretação da complementariedade, seguindo a ideia do positivismo lógico, como fica um pouco mais claro no momento em que diz:

Só porque não podemos medir a posição e o momento precisamente não significa a priori que não podemos falar sobre eles. Significa apenas que não precisamos falar deles. A situação em ciência é essa: Um conceito ou uma ideia que não pode ser medida ou não pode ser associada diretamente a um experimento pode ou não ser útil. Não precisa existir na teoria [13, p. 2-8, grifo do autor].

Ao expressar "pode ou não ser útil", Feynman, de novo, parece abrir a possibilidade, em nossa interpretação, de que um conceito ou uma ideia possa assumir outros significados no bojo de alguma teoria, se esta viesse a existir, o que revela um espírito versátil do autor. Portanto, sintetizando, embora a apresentação geral da Física Quântica seja pragmática e instrumentalista, em consonância com a tendência pedagógica do período de Guerra Fria, Feynman consegue imprimir reflexões profundas e importantes sobre questões fundamentais da Física Quântica.

\subsection{Análise da Obra QED: e estranha teoria da luz e da matéria}

Conforme discutimos na seção anterior, a visão epistemológica inferida do enunciado de Feynman ao falar da Física Quântica é, majoritariamente, comprometida com uma voz positivista, e sua abordagem pedagógica é bastante pragmática e instrumentalista (ainda que haja reflexões filosóficas relevantes no seu enunciado) - o que parece ser uma resposta ao contexto extra verbal em que Feynman se encontrava - o que exemplifica a noção de que a Epistemologia (e, nesse caso, a pedagogia) não podem ser entendidas apartadas da política, como reconhecem diversos Estudos das Ciências [19]. Como discutiremos nessa seção, em obras posteriores, após o auge da Guerra Fria, as vozes veiculadas nos enunciados de Feynman se comprometem com outras visões de mundo, refletindo uma mudança de projeto de fala do locutor.

A obra QED: a estranha teoria da luz e da matéria $[20]^{6}$ foi escrita 20 anos mais tarde das Lições, Feynman já havia trabalhado por um longo tempo com a Eletrodinâmica Quântica que, como veremos, é uma área específica e já havia começado a desaceleração da corrida armamentista. O livro contém quatro lições (Quadro 3) que foram pensadas para atender a um pedido de Alix Mautner, esposa de seu amigo de infância Leonard Mautner. Alix trabalhava com literatura inglesa, mas tinha

${ }^{6}$ Neste trabalho, foi utilizada a edição publicada em italiano. No Brasil, em 2015, o livro foi publicado em português pela editora Gradiva. 
Quadro 3: Sobre a estrutura do livro $Q E D$, que se compõe de quatro capítulos.

\begin{tabular}{ll}
\hline Capítulo & Título \\
\hline 1 & Introdução \\
\hline 2 & Os fótons: partículas de luz \\
\hline 3 & Os elétrons e suas interações \\
\hline 4 & Conclusões indefinidas \\
\hline
\end{tabular}

imensa curiosidade por história da ciência; ela morreu em 1982 e em sua homenagem foi criada uma fundação com o objetivo de financiar conferências anuais para comunicar ao público as conquistas da ciência; Feynman aceitou o convite de fazer a primeira série de lições com o objetivo de que pudessem ser compreensíveis a não físicos, como Alix, ou mesmo estudantes de física.

Como dito, o objetivo destas novas lições é a divulgação científica (e não mais formação de engenheiros e cientistas), e Feynman afirma se esforçar para apresentar ideias complexas que os físicos desenvolvem para explicar a natureza; lições que tinham base em aulas por ele ministradas na University of California, mas foram reescritas de maneira que um público de não especialistas pudesse compreendê-las. Embora, como expõe Ralph Leighton no prefácio da edição italiana de 1989, é possível que sua leitura revele mesmo aos que já estudaram física, o que há atrás dos cálculos complicados.

A versão da obra que analisamos está em italiano, de maneira que todas as citações serão traduzidas (traduções livres nossas) já que o italiano é uma língua menos comum aos estudantes do que o inglês. Feynman expressa sua intencionalidade de alcançar o público já no início da primeira lição:

Contrariamente ao que se faz em lições deste gênero, a parte da física da qual falarei já é conhecida. O público é sempre curioso em saber o que há de novo (...). Quer sempre saber o que não sabemos, e não nos dá a possibilidade de falar de teorias que conhecemos bem. Assim, em vez de confundi-los com um monte de teorias "meio-cruas", escolhi um argumento que tem sido analisado a fundo e que pertence a uma área da física que eu acho maravilhosa: a eletrodinâmica quântica, ou abreviadamente QED. Nesta lição me proponho primeiro a escrever com o maior cuidado possível, a estranha teoria da luz e da matéria, ou especificamente, da interação da luz com os elétrons [20, p. 17-18].

Percebe-se como a escolha lexical revela uma visão contrária ao positivismo ingênuo (doutrina que crê que teorias científicas são descobertas, ou desveladas a partir da observação cuidadosa da natureza e, portanto, são verdades inquestionáveis) quando admite que no início o conhecimento é incerto e as teorias são "meio-cruas".

Diferentemente das Lições de Física que não pereciam ter compromisso com ordenamento cronológico dos estudos físicos, o texto começa com um breve retrospecto histórico; iniciando pelas leis do movimento de Newton, passando pelos fenômenos elétricos e magnéticos, unificados por Maxwell, e explicando que a tentativa de conceber o movimento do elétron em torno do núcleo atômico da mesma forma como Newton explicava o movimento da Terra em torno do Sul foi um rotundo erro, e que para dar conta desse fenômeno foi preciso desenvolver uma nova teoria: a Mecânica Quântica; mas, acrescenta que ainda faltava explicar a interação da luz com a matéria, e a partir de 1929 foi, então, desenvolvida a Eletrodinâmica Quântica; fala também que Dirac que, com base na teoria da relatividade, formulou uma teoria relativística do elétron e explica que várias correções foram necessárias. Na sequência, surpreende ao expressar:

Devo dizer que a história que acabo de delinear é "uma história da física vista por um físico", uma história, isto é, que nunca é inteiramente verdade, uma espécie de históriamito convencional que os físicos contam aos seus estudantes, os quais contam aos seus estudantes, e que não é necessariamente ligada ao desenvolvimento real (para mim, entretanto, desconhecido!) [20, p.20].

Aqui, se por um lado, a escolha lexical parecer revelar desconhecimento do cientista do real desenvolvimento histórico da ciência, o que é consistente com a despreocupação de Feynman com a história e a epistemologia já reveladas na análise precedente, por outro lado, ele surpreende ao afirmar que a história da ciência "contada em aulas" é incompleta, e que oculta muitos detalhes, o que esclarece o aparente "descaso" com a filosofia da ciência nas Lições de Fúsica; Raicik e Peduzzi [21] afirmam que apenas resgates históricos cuidadosos podem revelar a conexão entre as convicções teóricas do pesquisador e a experimentação, além de valorizar o papel da experimentação, revelar erros e tentativas frustrada, bem como a pluralidade metodológica utilizada em uma dada descoberta.

Se nós, educadores preocupados com o ensino de física não nos ativermos a estes aspectos, que podem ser muito valiosos para a compreensão dos conteúdos físicos, poderemos facilmente cair no que Feynman parece querer chamar a atenção, ou seja, contar uma "história da física vista por um físico", abreviada, uma "históriamito". Tal declaração de Feynman pode ainda indicar o conhecimento do autor sobre reflexões feitas por filósofos e historiadores da ciência sobre a história da ciência contada nas aulas de Física, como apontam Kuhn [22] e Brush [23].

Nessa mesma lição, fala das utilidades da eletrodinâmica quântica e afirma que é um protótipo para as teorias mais recentes que buscam explicar os fenômenos nucleares. Feynman expressa com clareza como a física é uma construção humana, em constante (re)interpretação, que é inconclusa e sujeita a correções como defendem diversos epistemólogos desde meados do século passado (Popper [24]; Kuhn [22]; Feyerabend [25]; Bachelard [26] e muitos outros) ao escrever "Nós físicos estamos sempre atentos 
em verificar se há qualquer dificuldade em uma teoria, e o bonito está exatamente aqui, porque uma eventual dificuldade é algo muito interessante. Mas até agora a eletrodinâmica quântica não revelou nenhuma falha, é, portanto, diria, a joia da física..." [20, p.23].

Há de se destacar a relevância da $Q E D$, segundo Schweber [27], e alguns percalços que ela sofreu e como isso é um enriquecimento para a discussão epistemológica. Comecemos essa discussão relembrando a estrutura fina pelo desdobramento das linhas de energia do átomo de hidrogênio, por exemplo (o que é diferente da estrutura hiperfina, que também é um desdobramento das estruturas de nível, mas devido à interação com o momento magnético). A teoria de Schroedinger não trazia nenhuma informação sobre o desdobramento das linhas do espectro em estrutura fina em um primeiro momento, agora a teoria de Dirac prevê esse desdobramento com grande precisão (de cerca de uma parte em cem mil). A $Q E D$ também prevê esse fenômeno, mas com uma precisão incrível (de uma parte em $10^{8}$ ). A discussão sobre a precisão é algo a se destacar, pois segundo o filósofo da ciência Larry Laudan [28, p. 55], "um determinante considerável da importância das anomalias é o grau de discrepância entre o resultado experimental observado e a predição teórica".

Relembremos também o fator de giro quando se estuda os momentos magnéticos. Quando fazíamos o cálculo à maneira semiclássica, era preciso colocar "à mão" uma correção para que o momento de dipolo magnético orbital fosse equivalente aos valores experimentais, essa correção era o fator orbital (ou fator de giro orbital, $g_{l}$ ), o qual deveria ser de valor 2 ou aproximado:

$$
\overrightarrow{\mu_{l}}=-\frac{g_{l} \mu_{B}}{\hbar} \vec{L}
$$

Sendo que $\mu_{B}$ é o magnéton de Bohr, $\vec{L}$ o momentum angular e $\hbar$ a constante de Planck reduzida. Relação semelhante nós temos para o momento de dipolo magnético intrínseco (spin). Quando feito à maneira semiclássica, precisamos impor esse valor, porém com a teoria de Dirac, esse valor era predito como sendo exatamente igual a dois, de fato um avanço em relação à tradição de pesquisa, ou paradigma, anterior. Porém, a $Q E D$ nos trará algo ainda melhor. Ela também prevê o fator orbital, mas agora como sendo um pouco maior do que dois, de forma que ao dividirmos por dois temos:

$$
g / 2=1,00115965218085(76)
$$

E isso nos dá uma precisão melhor que de uma parte em um trilhão (os dois dígitos em parênteses indicam a incerteza nos dois últimos dígitos da medida). Sem dúvida é algo que chama muito a atenção, pois é a medida que temos maior precisão em toda a física, predita pela $Q E D$. Por essa razão é conhecida como a "joia da física" [20, p. 20]. Ela sem dúvida tem uma capacidade enorme de resolução de muitos problemas dentro de seu domínio de aplicabilidade. Porém, essa joia se mostrou (na verdade ainda se mostra), com algumas limitações, não tanto por ser uma teoria limitada, mas por tratar de áreas que
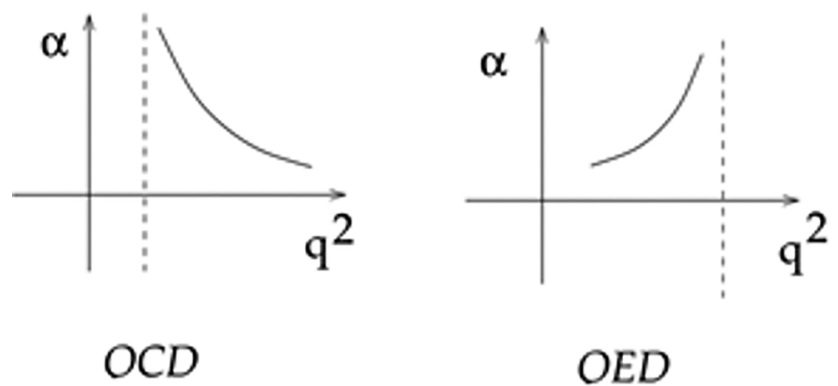

Figura 1: $O$ polo de Landau ilustrado na reta pontilhada para a $Q C D$ e para a $Q E D$ [29].

são fronteira de conhecimento e não termos sequer bons aparelhos para tais medições. Trata-se das regiões de altas energias (para a escala de Planck), onde a $Q E D$ diverge, e trabalhar com ela torna-se uma tarefa quase impossível nessa região. Por não ter uma capacidade de resolver os problemas com os quais a quântica se deparava nas escalas de altas energias, Landau e colaboradores decidiram parar de trabalhar com essa tradição de pesquisa, buscando alguma que fosse mais eficaz, uma dessas concorrentes poderia ser a $Q C D$, por exemplo, que ao contrário da $Q E D$ diverge para baixas energias 7 como ilustrado na Figura 1. Hoje, ironicamente, essa região de divergência é conhecida como polo de Landau.

Com isso, a $Q E D^{8}$ se mostra como sendo um avanço em relação à Dirac, que se mostra como um avanço em relação a Schroedinger. Passo a passo, a comunidade foi trocando de tradição de pesquisa para outras que resolvessem mais problemas [28]. Na situação investigada neste trabalho, tradições de pesquisa mais evoluídas são teorias quânticas de campos, como a $Q E D$, as quais incluem efeitos relativísticos.

Assim, destacada a importância da $Q E D$, vê-se em Feynman entusiasmo e certa responsabilidade, no sentido

\footnotetext{
7 Se diverge ou não para baixas energias é uma discussão recente. A comunidade científica se encaminha para uma concordância que na verdade ela converge para um valor inicial [30]. Além do mais, Gerard't Hooft - prêmio Nobel de física em 1999 por elucidar a estrutura quântica de interações eletrofracas - demonstrou que a $Q C D$ é uma teoria renormalizável. Segundo ele indica [31], se existe uma teoria fundamental e que servirá de exemplo para outras, essa teoria pode ser a $Q C D$, por ter liberdade assintótica. Entende-se que uma teoria unificada, aquela que será a teoria das teorias, precisa ter liberdade assintótica. Aqui reside todo o problema da unificação da física, aqueles pesquisadores que se debruçam sobre esse problema têm geralmente poucos artigos publicados, por ser uma área tão complicada, mas em compensação são os que podem ganhar um prêmio Nobel e resolver um problema de destaque. Serão como Newton, encontrarão aplausos quase universais para suas tradições de pesquisa, por sua capacidade de "resolver muitos problemas empíricos cruciais" [28, p. 64]. Até lá sofrerão um tanto. $8 \mathrm{Na}$ imagem da figura 2 tem-se capa do livro mencionado sobre a $Q E D$, de Schweber [27]. É interessante trazê-la por ilustrar os três criadores da $Q E D$, Tomonaga, Schwinger e Feynman. À época, os três acreditavam que estavam fazendo coisas diferentes e cada um poderia defender que merecia o prêmio Nobel individualmente. Dyson, ao mostrar de maneira semelhante à Bethe a renormalização da QED, pôde demonstrar que os três cientistas na verdade estavam fazendo a mesma coisa, apenas de maneiras diferentes. No fim, os três ganharam o Nobel de física ao passo que Dyson nada recebeu.
} 


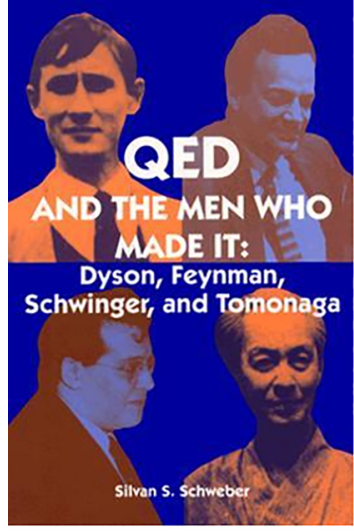

(a)

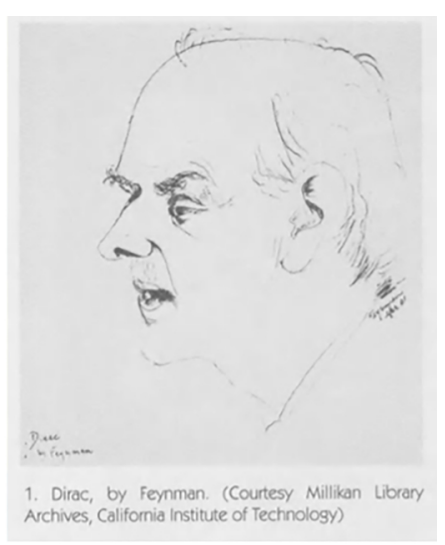

(b)
Figura 2: Os homens que fizeram a $Q E D$, e também Dyson. Na mesma obra há uma caricatura de Dirac, feita por Feynman [27].

de tentar capturar o público para se interessar pelo tema. Para esclarecer melhor o argumento da lição, faz uma analogia:

Se se imagina o mundo físico como um palco, os atores não são só os elétrons, que nos átomos estão na parte externa do núcleo, mas também os quarks, os glúons e as dezenas de partículas que se encontram no seu interior. E estes "atores" embora muito diferentes um dos outros, têm todos o mesmo estilo, um estilo estranho e peculiar, o estilo "quântico" [20, p. 23].

Para convencer o público a não ir embora, e continuar ouvindo a palestra, Feynman expressa dois argumentos, que também são importantes para o ensino de física: primeiro, esclarece que palavras como "trabalho", "ação", "energia" e "luz" são usadas pelos físicos com sentidos diferentes daqueles comumente conhecidos no cotidiano, e alerta que este é um erro no qual é muito fácil incorrer, isto é, usar outros sentidos sem se dar conta e, como palestrante, promete controlar-se; segundo, afirma que ao explicar "como" funciona a natureza, o público não compreende "por que" ela funciona desta forma, mas tranquiliza seu público dizendo que isto não o compreende ninguém, e justifica esta afirmação através de um enunciado que, na verdade, oferece uma visão (sua visão!) de teoria científica, que não deixa de ser uma possibilidade a ser refletida:

Os físicos aprenderam a conviver com esse problema: compreenderam que o ponto essencial não é se se pode gostar ou não de uma teoria, mas se ela fornece previsões que estão de acordo com os experimentos. A riqueza filosófica, a facilidade, a racionalidade de uma teoria são todas coisas que não interessam. Do ponto de vista do bom senso, a eletrodinâmica quântica descreve uma natureza absurda. Contudo, está em perfeito acordo com os dados experimentais. Espero que aceitem a natureza pelo que é: absurda. Para mim, falar dessa absurdidade é um divertimento, porque eu a acho encantadora [20, p. 25].

Como se vê, talvez seja essa escolha lexical que torne as lições de Feynman tão apreciadas mundo afora, embora nessa passagem ele reafirme sua não adesão à filosofia da ciência. Fazendo uso de inúmeras analogias. É de destacar, contudo, que suas escolhas não incluem analogias que classicamente encontramos nos livros didáticos de física, quer do ensino básico ou superior. Por exemplo, ao falar da natureza corpuscular da luz/fótons, afirma que:

A luz é, portanto, um pouco como a chuva, é feita de inúmeras "gotas" chamadas fótons, e quando ela é de uma única cor [a luz], suas "gotas" têm todas a mesma dimensão." [...] Repito: a luz se apresenta sob a forma de partículas. É muito importante esclarecer este ponto, especialmente para quem foi à escola, onde provavelmente lhe foi ensinado que a luz se comporta como onda. Eu lhes digo, em vez disso, que a luz se comporta como partículas [20, p. 29-30].

Depois de esclarecer esse caráter da luz, passa a explicar, do ponto de vista da eletrodinâmica quântica, fenômenos como a reflexão e refração da luz. Descreve a reflexão parcial da luz em um experimento onde uma fonte luminosa ilumina um vidro, e chama a atenção para uma "simplificação" noticiando que "fará de conta" que a reflexão só ocorre na superfície, mas avisa que um pedaço de vidro é de uma complexidade monstruosa e que quando a luz nele incide, um número enorme de elétrons se agita de modo inacreditável. Noticia que para cada 100 fótons enviados pela fonte, a experiência mostra que quatro (4) são refletidos e 96 atravessam o vidro. A questão, então, passa a ser: como o fóton "decide" se atravessa o vidro ou salta de volta e é refletido?

Aqui, de novo ele desafia a filosofia ao dizer que "Alguns filósofos têm sustentado que se as mesmas condições não produzem sempre o mesmo efeito, as previsões resultam impossíveis e a ciência mesma colapsa" [20, p. 34].Ele refuta essa assertiva. Diz que estamos diante de um caso em que fótons idênticos incidem na mesma direção, sobre o mesmo pedaço de vidro, mas não temos condições de prever se um dado fóton chegará em A ou em B; o que podemos é prever que, em média, cada 100 fótons que incidem no vidro 4 são refletidos pela superfície, ou seja, a natureza permite apenas calcular a probabilidade de um evento ocorrer e o que precisamos fazer é encontrar uma teoria que explique este comportamento. Mesmo assim, afirma ele, a ciência ainda está de pé.

Depois ele complexifica esse comportamento "absurdo", como ele afirma, dos fótons descrevendo um segundo experimento trocando o pedaço de vidro por uma lâmina de vidro, de modo que agora os fótons encontram duas superfícies paralelas onde podem ser refletidos; isto sugere que o total de fótons refletidos seria o dobro, ou seja, $8 \%$. Contudo, os resultados de medidas cuidadosas mostram 
que há uma relação entre a espessura da lâmina de vidro e a reflexão parcial, de maneira que com o aumento da espessura do vidro, a reflexão varia ciclicamente entre zero e $16 \%$. Volta a falar de Newton, pois este se debruçou, em vão, na tentativa de explicar corpuscularmente o que a teoria ondulatória depois explicou facilmente, revelando, assim, uma dualidade ondulatória-corpuscular da luz. Contudo, argumenta Feynman, ainda hoje não há um modelo intuitivo para explicar a estranha propriedade da reflexão parcial da luz devida a duas superfícies; e o que se pode fazer é calcular a probabilidade de um fóton ser refletido; a eletrodinâmica quântica fornece um método para "calcular o valor correto da probabilidade que a luz seja refletida de um vidro da dada espessura, porque esta é a única coisa que os físicos sabem fazer" [20, p. 40]. Ressalta que a pergunta "como o fóton faz para decidir se reflete ou atravessa?" não faz sentido. E segue:

Agora fiquem firmes, não porque o que se deve fazer seja difícil, mas porque é absolutamente ridículo: você tem que desenhar muitas pequenas setas em uma folha de papel, e é isso! [20, p. 40].

Feynman dedica o restante dessa lição para explicar que a probabilidade de um evento é igual ao quadrado do comprimento da seta (em outras palavras: é a área da figura que as setas formam). Assim, no primeiro experimento o tamanho da seta é 0,2 porque 0,2 ao quadrado é igual a 0,04 , ou $4 \%$. No segundo experimento, que depende da espessura da lâmina de vidro, o comprimento das setas deve variar de zero a 0,4 (probabilidade entre zero e 16\%); deve-se combinar ("somar") duas flechas (dado que há duas superfícies, uma anterior e outra posterior); as setas (de diferentes comprimentos) são desenhadas de forma que a ponta de uma esteja na cauda da outra (quaisquer que sejam as direções em que são desenhadas), sendo que a probabilidade do fóton refletir será dada pela "soma" (seta resultante); a direção em que se deve desenhar as flechas é dada pela direção do indicador (ou ponteiro) de um cronômetro que gira enquanto o fóton está viajando, sendo que para a superfície frontal a seta é desenhada em direção oposta àquela em que parou o ponteiro do cronômetro quando o fóton atingiu a superfície. Por exemplo, haverá uma espessura tal em que a seta da superfície frontal será igual, em comprimento e direção, mas de sentido oposto à seta da superfície posterior, tal que a soma das setas será zero - isto indica que há uma espessura em que a probabilidade de reflexão do fóton é zero; haverá uma espessura da lâmina em que as posições das setas relativas à reflexão formarão um ângulo de $90^{\circ}$, de maneira que a soma será a hipotenusa do triângulo retângulo (teorema de Pitágoras) e o seu quadrado dará a probabilidade exata de $8 \%$, e assim por diante.

Fiz ver, portanto, como as estranhas propriedades da reflexão parcial podem ser descritas exatamente desenhando algumas banais flechas numa folha de papel. Em linguagem técnica estas flechas são chamadas "amplitude de probabilidade" e, certamente me faz sentir mais importante afirmar que estou "calculando a amplitude de probabilidade de um evento". Prefiro, porém, ser mais honesto e dizer que estou considerando as flechas cujo quadrado representa a probabilidade de que o evento ocorra [20, p. 49].

Feynman encerra a primeira lição deste livro falando das lindas cores que formam as bolhas de sabão ou uma poça de água com a superfície coberta com gotas de óleo na pista para cuja explicação é idêntica, já que formam filmes finos, como se fossem finas lâminas de vidro que refletem a luz branca produzindo uma multiplicidade de cores.

Na segunda lição o autor explica a partir da eletrodinâmica quântica a reflexão da luz num espelho, porque a luz viaja em linha reta e porque focaliza quando atravessa uma lente. Como ele mesmo diz "De fato, a maior dificuldade que encontrei ao preparar estas lições foi resistir à tentação de discutir todas as propriedades da luz que em geral laboriosamente vocês estudaram na escola. (...) Me limitarei àqueles fenômenos mais simples e mais comuns." [20, p. 57].

Percebe-se que Feynman tem uma capacidade e uma versatilidade de explicar coisas complexas de maneira que pareçam simples, pelo menos compreensíveis ao público, mas sempre com uma preocupação responsiva, buscando contextualizar seu discurso para que as lições consigam explicar fenômenos cotidianos de beleza rara e que dão sentido às teorias. Embora explicitamente se assuma avesso às considerações filosóficas, ele acaba fazendo excelentes contribuições justamente em relação à natureza da ciência e que são úteis para o ensino.

\subsection{Análise da Obra Os Melhores Textos de Richard P. Feynman}

A última obra que analisamos trata de uma coleção de pequenos textos, referentes a entrevistas, palestras e artigos curtos que ficaram famosos por serem de fácil compreensão para um público não especializado, semelhante a obra anterior. O livro contém treze capítulos (Quadro 4), os quais analisamos e dos quais destacamos os aspectos mais frutíferos à discussão do presente trabalho.

O objetivo desta obra também é distinto das Lições da época da Guerra Fria, que analisamos na primeira parte deste texto, de maneira que, com as ferramentas da análise do discurso referente ao estudo do contexto histórico, nota-se que visavam ou à introdução do conteúdo científico para um público iniciado na academia ou à divulgação científica. Aqui se tem um apanhado das mais importantes entrevistas ou palestras, como já indicado, publicado postumamente em 1999, muitos anos após a ministração das Lições de Fúsica e quatorze anos após a obra acerca da $Q E D$, com a grande maioria das palestras e entrevistas sendo ministradas e concedidas a partir do final da década de setenta, de forma que o Físico já estava muito mais despretensioso e aventurando-se em 
Quadro 4: Sobre a estrutura do livro Os Melhores Textos de Richard P. Feynman, que se compõe de treze capítulos.

\begin{tabular}{ll}
\hline Capítulo & Título \\
\hline 1 & O prazer de descobrir as coisas \\
\hline 2 & Computadores do futuro \\
\hline 3 & Los Alamos visto de baixo \\
\hline 4 & $\begin{array}{l}\text { Qual é e qual deveria ser o papel da cultura cien- } \\
\text { tífica na sociedade moderna }\end{array}$ \\
\hline 5 & Há muito espaço no fundo \\
\hline 7 & O valor da ciência \\
\hline 8 & Relatório minoritário de Richard P. Feynman no \\
& inquérito sobre o ônibus espacial Challenger \\
\hline 10 & O que é ciência? \\
\hline & O homem mais inteligente do mundo \\
\hline 11 & cia, pseudociência e como aprender a não enganar \\
\hline 12 & E si mesmo \\
\hline 13 & Richo simples quanto um, dois, três \\
\hline
\end{tabular}

novas áreas de discussões e reflexões, além de ser um período posterior ao auge da Guerra Fria, não havendo mais a urgência na formação de engenheiros e cientistas. Logo no começo do livro, o autor expressa sua percepção sobre como sua própria relação com as ciências exatas e humanas muda ao longo dos anos, pois reflete intenções de diferentes momentos com respeito à ciência:

Sempre fui muito unilateral com a ciência, e quando era novo concentrava nela quase todo o meu esforço. Não tinha tempo para aprender e não tinha muita paciência com o que chamavam de "humanidades". (...) Só depois, quando fiquei mais velho, quando fiquei mais tranquilo, é que me abri um pouquinho. [32, p. 16].

Afirmar que Feynman adotou durante a ministração das Lições uma visão positivista é razoável, mas não se pode dizer que tenha sempre sido assim; quanto ao seu posicionamento epistemológico ao menos no começo, dado que reflete as diferentes intenções que marcaram sua carreira e seus diferentes compromissos sociopolíticos, aparece um intencional descaso para com "o que é chamado de humanidades", que se refletiu em sua carreira como professor, na qual, como já elucidado, transmitia uma história "que nunca é inteiramente verdade, uma espécie de história-mito convencional que os físicos contam aos seus estudantes" [20, p.20]. Para explicar por que "desprezava" as humanidades, Feynman apresenta uma interpretação de sua própria história, enfatizando que seu gosto pela física, aliado a uma atitude egoísta, o motivavam a performar um certo personagem:

[...] se a gente trabalha administrando alguma coisa, não tem esse tempo contínuo. Aí inventei um outro mito pra mim: de que sou irresponsável. Digo a todo mundo que não faço nada. Se alguém me pede para participar de um comitê para cuidar de matrículas, não, sou irresponsável, não dou a mínima para os alunos - é claro que dou a mínima para os alunos, mas sei que outra pessoa vai cuidar disso; e aí adoto a postura de "Let George Do It", postura que a gente não deveria assumir, tudo bem, porque não está certo, mas faço isso porque gosto de trabalhar com física e quero ver se ainda consigo, portanto sou egoísta, tá certo? Quero fazer a minha física. [32, p. 28].

Deve-se ter clareza que a narrativa histórica do autor não pode ser confundida com a história em si, mas como uma interpretação de sua trajetória. Assim, o descaso de Feynman com a filosofia e sua adesão a vozes positivistas nas Lições de Física, como narrado no trecho analisado, parece ser reflexo de uma privilegiação [12] da produção científica em detrimento a outras formas de conhecimento, o que seria natural no período de Guerra Fria. Feynman indica que prefere deixar essas discussões para outra pessoa interessada, alguém como o hipotético George, um nome fictício para ilustrar que haverá outras pessoas que farão esse trabalho. Feynman, ademais, complementa o que lhe desagrada na Filosofia:

Não é a Filosofia que me pega, é a pompa. Se eles rissem de si mesmos... Se eles dissessem: "Acho que é assim, mas Leipzig achou que era assado, e também foi uma boa tentativa." Se explicassem que é seu melhor palpite... Mas pouquíssimos deles fazem isso; ao contrário, eles aproveitam a possibilidade de que talvez não haja nenhuma partícula fundamental e dizem que a gente deveria parar de trabalhar e ponderar com grande profundidade. "Você não pensou com profundidade suficiente, deixe-me primeiro definir a palavra para você." Pois bem, vou investigar sem definir! [32, p. 138, grifo do autor].

Mais uma vez, o posicionamento de Feynman é fortemente ancorado no seu contexto extra verbal. A diferenciação que Feynman faz nos trechos analisados entre ciências exatas e humanas e a caracterização dos filósofos como intelectuais pomposos lembra o muito difundido livro de C. P. Snow [33], As Duas Culturas, no qual o autor afirma que as humanidades não reconhecem os cientistas e engenheiros como intelectuais. Nesse sentido, podemos afirmar que a fala de Feynman dialoga com a obra de Snow e, a partir dessa visão dicotômica (ciências humanas versus exatas) ele interpreta sua própria trajetória. Em contraposição à sua visão da Filosofia como algo pomposo, Feynman apresenta sua visão de ciência:

O cientista nunca tem certeza. Todos sabemos disso. Sabemos que todas as nossas afirmativas são afirmativas aproximadas com vários graus de certeza; que quando se faz uma afirmativa, a questão não é se ela é verdadeira ou falsa, mas qual é a probabilidade de ser verdadeira ou falsa [32, p. 86]. 
Como já foi evidenciado na obra a respeito da $Q E D$, Feynman novamente nos remete à ideia da ciência como construção humana, pois é inconclusa, sempre sujeita a mudanças e, para que essas mudanças ocorram, a dúvida é necessária. Não é adequado questionar se uma teoria é verdadeira ou falsa, mas sim o quão provável é de ser verdadeira ou falsa, de forma que a $Q E D$ é no momento a teoria com maior probabilidade de conter verdade em seu conteúdo, visão essa que remete à noção de conteúdo-verdade e de aproximação de verdade em Popper [24], este que ainda destaca a preocupação em chegar a uma verdade absoluta nas ciências como não sendo algo verossímil, uma vez que "nossa ignorância é infinita. O perigo de completarmos nosso conhecimento não é real" [24, p.242]. Deve-se ressaltar, entretanto, que tal visão sobre a natureza da ciência é, no mínimo, uma idealização bastante abstrata, distante da prática científica concreta. Como discute Bruno Latour [34], deve-se diferenciar a ciência oficial da ciência oficiosa. Feynman fala da ciência oficial, aquela que os cientistas gostam de narrar nos seus discursos e que, talvez, expresse o ideal científico como expresso no início do século XX por Bachelard [35], mas que em pouco se assemelha à ciência que encontramos nos estudos históricos e etnográficos como apontam Latour e Woolgar [36], Kuhn [22], Feyerabend [25], entre tantos outros. Em especial, Thomas Kuhn [37] discute em profundidade a noção de que o dogmatismo é uma característica essencial para a evolução da ciência. Numa visão um tanto popperiana, Feynman enfatiza:

E quando tem uma baita certeza de qual será o resultado, tem alguma dúvida. Descobrimos que, para progredir, é importantíssimo admitir a ignorância e deixar espaço para dúvidas. O conhecimento científico é um corpo de afirmativas com graus variados de certeza: algumas muito incertas, outras quase certas, nenhuma absolutamente certa. [32, p. 110, grifo do autor].

Certamente a dúvida, o desejo de descobrir algo novo que não se encaixa no padrão vigente, é uma característica marcante na visão de ciência de Feynman. Para ele, "Aquilo que não se encaixa é que é mais interessante, a parte que não acontece do jeito que a gente esperava. Além disso, podemos ter revoluções na física: depois." [32, p.25]. Não obstante a evocação do termo tipicamente kuhniano de revolução [22], há ainda o destaque para aquilo que não se encaixa, em termos de Kuhn, no quebracabeça vigente da ciência normal, e que acaba levando a uma revolução pela adequação a um novo paradigma. Feynman, nesse sentido, parece, neste trecho, dialogar com a visão kuhniana de ciência, que é uma visão um tanto comum na comunidade científica, como destacado pelo físico Max Born:

Quem quer que observe de maneira desapegada o desenvolvimento das ciências exatas deve ser impressionado por duas características contraditórias. Por um lado, toda a ciência natural exibe uma imagem de crescimento contínuo e saudável, de progresso e construção inconfundíveis [...]. No entanto, por outro lado, observa-se, em intervalos não raros, a ocorrência de revoltas nos conceitos básicos da física, revoluções reais no mundo das idéias, nas quais todo o nosso conhecimento anterior parece ser varrido e uma nova época de investigação para ser inaugurado [38, p. 17, grifo nosso].

Para um físico atento ao desenvolvimento da ciência, como Born comumente fazia, ou Feynman quando passou a dedicar mais tempo a essas reflexões, certamente é perceptível o desenvolvimento não linear da ciência, com saltos referentes às revoluções. Assim, tendo destacado o importante papel do questionamento e da dúvida com relação às teorias antigas e a necessidade de não tomar tudo como absolutamente verdadeiro dentro da física, Feynman nos proporciona sua melhor definição para o que é ciência, afinal:

E é isso que a ciência é: o resultado da descoberta de que vale a pena conferir de novo com novas experiências diretas, sem confiar necessariamente na experiência da raça vinda do passado. É assim que vejo. É minha melhor definição. [32, p. 132].

Assim, parece que Feynman apresenta forte influência de visões racionalistas (como a de Popper) hibridizada com uma voz kuhniana, uma vez que reconhece a existência de rupturas (pode-se dizer que Feynman dialoga com Popper e Kuhn ${ }^{9}$ ). Deve-se ressaltar, ademais, que a descrição de Feynman sobre a ciência é puramente internalista. Ele descreve a ciência como uma atividade epistêmica, sem fazer nenhuma menção à sua relação com a sociedade. Tal visão apolitizada da ciência é extremamente popular entre cientistas, mesmo entre aqueles que se engajaram em atividades "políticas" como o próprio Feynman no Projeto Manhattan. Tal apagamento das relações entre ciência e sociedade é tão antigo quanto a própria ciência como apontam as discussões mais recentes de Bruno Latour [39].

A relação de Feynman com epistemologias atuais ainda é mais bem evidenciada quando se tem em mente a importância do questionamento na regra metodológica da contra-indução, na epistemologia de Paul Feyerabend. Para o filosófico austríaco (2011, p. 38) [25], seguir a contra-indução significa dizer que "o cientista [...] tem de tentar aperfeiçoar, em vez de destacar, as concepções que fracassaram nessa competição." Para Feyerabend, um claro exemplo de cientista que seguia o princípio da contra-indução era Bohr, pois (2011, p. 38) [25] "ele jamais tentava esboçar um quadro acabado, mas percorria pacientemente todas as fases do desenvolvimento de um problema [...] e jamais considerava resultados obtidos

\footnotetext{
9 Ao dizer que Feynman dialoga com Karl Popper e Thomas Kuhn, o fazemos no sentido do diálogo de enunciados no grande tempo da Cultura. Isso não significa que Feynman, de fato, leu ou conhecia Popper ou Kuhn, embora isso fosse possível.
} 
como qualquer outra coisa que não pontos de partida para novas pesquisas". Assim Bohr pode ser mencionado como um físico que seguia a metodologia pluralista mencionada por Feyerabend, e assim também o pode ser Feynman, uma vez que afirma:

[...] Num dia estarei convencido de que há um certo tipo de simetria em que todo mundo acredita, no dia seguinte tentarei imaginar as consequências caso não haja e todo mundo seja maluco, menos eu. Mas o mais incomum nos bons cientistas é que, enquanto estão fazendo seja lá o que estejam fazendo, eles não têm tanta certeza de si quanto os outros costumam ter. Conseguem conviver com a dúvida constante [...]. [32, p. 140].

Tal como Bohr, Feynman também não desenhava um "quadro acabado" para uma teoria, por mais brilhante que ela pareça ser, como é o caso da $Q E D$, mas procurava pontos em que as teorias pudessem falhar, o que pode levar a novos profícuos avanços na ciência. Por fim, a obra é encerrada com um posicionamento acerca da religião e possíveis relações com a ciência. Para tanto, Feynman, de maneira semelhante ao discurso adotado nas Lições de Física, adota um discurso de cunho positivista, além de bastante respeitoso às diferentes crenças:

Eu não acredito que a ciência possa negar a existência de Deus; eu acredito que isso é impossível. E se é impossível, a crença na ciência e num Deus - um Deus comum da religião - não seria uma possibilidade coerente? Sim, é coerente. [32, p. 164].

Remonta-se aqui a discussão acerca das Lições; não é possível discutir aquilo que não pode ser medido. A ciência não pode, para Feynman, fazer qualquer medição para provar ou não a existência de uma divindade, logo, a crença ou fé em uma divindade criadora é algo totalmente consistente nessa perspectiva. Note-se que ele se utiliza de um discurso de cunho positivista, mas após todas as entrevistas, palestras e trabalhos destacados até aqui, é evidente que ele não o seja e esse é um fator importante a ser destacado, que fica evidente com uma abordagem mais ampla do trabalho de Feynman.

Para Feynman, a ciência é paciência, paciência por desvendar as maravilhas que vemos na natureza ou no laboratório, manifestando-se na forma de padrões matemáticos e leis, porém, estas nunca absolutamente certas, sempre provisórias, mas levando cedo ou tarde a um progresso e uma influência marcante na sociedade, sendo que aquilo que deve mover o cientista não é o desejo de marcar seu nome por grandes e influentes feitos, riqueza, ou mesmo prêmios, para Feynman [32, p.24], "o prêmio é o prazer de descobrir a coisa, o barato da descoberta".

Por fim, a mensagem que se capta deste texto é que a carreira científica é uma atividade marcada pela incerteza e pela dúvida, que perpassa as barreiras da ciência e influencia inclusive a visão acerca da religião, levando o cientista a questionar e fazer avançar o conhecimento científico. Conhecimento este que, para Feynman, não pode ser tomado como "ruim" ou "bom", uma vez que "O conhecimento científico é um poder que permite fazer o bem ou o mal, mas não vem com instruções de uso. Esse poder tem valor evidente, ainda que o poder possa ser negado pelo que se faz". [32, 106]. Novamente, essa é uma visão apolitizada da ciência, refletindo o que é conhecido na literatura em ensino de Física como o mito da neutralidade científica [40]. É muito interessante que um cientista como Feynman, com uma profunda relação com a história sociopolítica de seu país e do mundo, reforce a noção de uma ciência neutra. Nesse sentido, sua prática científica e pedagógica são contraexemplos de seu próprio discurso.

\section{Considerações finais}

Existe uma parcela significativa de cientistas que considera que a filosofia da ciência não desempenha papel importante no desenvolvimento científico e por isso deve ser descartada. Richard Feynman em certos momentos, se mostrou adepto desta visão, como na colocação de que filosofia seria tão útil ao cientista quanto ornitologia é aos pássaros, além de muitas outras colocações que se atribuem a ele [3]. Mesmo que Feynman entenda a Filosofia da Ciência como secundária no ensino de física, como é refletido em algumas expressões que utiliza, sua abordagem é filosoficamente consistente ao longo de suas Lições, nas quais o autor adere principalmente à Interpretação de Copenhague (de influência positivista) Apesar disso, na mesma obra, o autor traz uma discussão filosófica em que apresenta uma tendência realista (contrária, portanto, à visão de Copenhague) e apresenta a Interpretação de Variáveis Ocultas como uma possibilidade de explicação para o comportamento quântico. Conforme discutido na literatura $[8,9,10]$, a visão positivista e uma visão pedagógica pragmática e instrumentalista, presentes nas Lições, são, também, uma resposta ao quadro sociopolítico da época, isto é, da década de 1960. Nas demais obras, publicadas anos depois, após o auge da Guerra Fria, vemos que Feynman se mostra mais aberto às discussões e reflexões de cunho filosófico, adotando um discurso que engloba diversos aspectos de teorias epistemológicas modernas. Apesar disso, Feynman, um cientista muito popular e influente no século XX, acaba por reforçar o chamado mito da neutralidade científica, contrariando sua própria trajetória científica e pedagógica (a qual foi altamente não neutra). Sua visão de ciência, nos últimos textos, desconsidera as relações dessa com a sociedade, e se aproxima da visão racionalista de Popper hibridizada com algumas noções kuhnianas.

Por fim, concluímos que as visões epistemológicas e ontológicas expressas nos enunciados de Feynman apresentam uma grande responsabilidade com relação aos contextos extra verbais em que se situavam. Isso equivale a dizer que a prática pedagógica de Feynman não era neutra; mas axiologicamente posicionada, com projetos de fala claros, com intencionalidade política. Nesse sentido, os enunciados analisados são um exemplo marcante 
da hibridização entre epistemologia e política, o que já é reconhecido pelos Estudos das Ciências (Science Studies) há décadas.

No presente trabalho, entretanto, evidenciamos tal hibridização no gênero do discurso dos textos didáticos e de divulgação científica, o que ainda é pouco realizado, ressaltando que a prática pedagógica está, também, atada às concepções de visão de mundo e responde ao contexto extra verbal em que é performada.

A qualidade e robustez conceitual das obras de Feynman é inquestionável. Sua contribuição para o Ensino de Física Quântica continua relevante e atual mesmo depois de décadas da apresentação das Lições. Seus posicionamentos filosóficos (epistemológicos, ontológicos, políticos) responsáveis ao seu contexto extra verbal, em nada diminuem o valor de seu legado, mas justamente ao contrário, enriquecem-no ainda mais. Os enunciados de Feynman revelam a complexidade da natureza científica, que jamais foi e jamais será neutra. Sua prática científica e pedagógica são ações humanas e, portanto, intencionais, direcionadas, expressivas. Mesmo o abstrato formalismo da Física Quântica não consegue escapar da humanidade em que é construído, isto é, a ciência física é fruto de um trabalho coletivo que apresenta certos estilos de pensamento, certos padrões que carregam a marca do seu tempo e do seu contexto.

\section{Referências}

[1] M.R. Matthews, Educational Philosophy and Theory 20, 67 (1988).

[2] J.L. Kincheloe e K. Tobin, Cultural Studies of Science of Science Education 4, 513 (2009).

[3] J.S. Jensen, Rever 13, 172 (2013).

[4] N.W. Lima, F. Ostermann e C. Cavalcanti, Caderno Brasileiro de Ensino de Física 34, 2 (2017).

[5] M. Bakhtin, Os Gêneros do Discurso (Editora 34, São Paulo, 2016).

[6] G.T. Souza, Introdução à Teoria do Enunciado Concreto do círculo Bakhtin/Volochinov/Medvedev (Universidade de São Paulo, São Paulo, 2002).

[7] V.N. Voloshinov, A estrutura do enunciado, disponível em http://pt.scribd.com/doc/81664106/BAKHTINEstrutura-Do-Enunciado, acessado em 03/04/2020.

[8] R. Nardi, Investigações em Ensino de Ciências 10, 63 (2005).

[9] D. Kaiser, Drawing Theories Apart: The dispersion of Feynmann's diagrams in Postwar Physics (Chicago University Press, Chicago, 2005).

[10] D. Kaiser, Pedagogy and the practice of science (The MIT Press, Cambridge, 2006).

[11] A. Veneu, G. Ferraz e F. Rezende, Ensaio: Pesquisa em Educação em Ciências 17, 126 (2015).

[12] J.V. Wertsch, Voices of the Mind: A Sociocultural Approach to Mediated Action ( Harvard University Press, Cambridge, 1993).

[13] R.P. Feynman, R. Leighton e M. Sands, Lições de Física de Feynman (Bookman, Porto Alegre, 2008), v. 3.

[14] F. Ostermann e M.A. Moreira, Investigação em Ensino de Ciências 5, 23 (2000).
[15] O. Pessoa Jr., Conceitos de Física Quântica (Livraria da Física, São Paulo, 2003).

[16] R.A. Martins e P.S. Rosa, História da teoria quântica: a dualidade onda-partícula, de Einstein a De Broglie (Livraria da Física, São Paulo, 2014).

[17] H.A. Bethe, The Road from Los Alamos. Master of Modern Physics (Simon and Schuster, New York, 1991), p. 241.

[18] W. Heisenberg, Physics and Philosophy: The Revolution in Modern Society (Penguin Books, London, 2005).

[19] B. Latour, A Esperança de Pandora (Editora da UNESP, São Paulo, 2017).

[20] R.P. Feynman, QED (Adelphi Edizion, Milano, 1989).

[21] A.C. Raicik e L.O.Q. Peduzzi, Revista Brasileira de Pesquisa em Educação em Ciências 16, 109 (2016).

[22] T. Kuhn, A estrutura das revoluções científicas (Perspectiva, São Paulo,1998).

[23] S.G. Brush, Science 183, 4130 (1974).

[24] K.R. Popper, Conjeturas e Refutações (Editora da UnB, Brasília, 1982).

[25] P.K. Feyerabend, Contra o Método (Editora Unesp, São Paulo, 2011).

[26] G. Bachelard, A filosofia do não (Editorial Presença, Lisboa, 1991).

[27] S.S. Schweber, QED and the Men Who Made It: Dyson, Feynman, Schwinger and Tomonaga (Princeton U.P., New Jersey, 1994).

[28] L. Laudan, O Progresso e seus Problemas: rumo a uma teoria do crescimento científico (Editora Unesp, São Paulo, 2011).

[29] H. Javadi, Difference between $Q E D$ and $Q C D$, disponível em https://www.researchgate.net/publication/ 315767276_Difference_between_QED_and_QCD, acessado em 03/04/2020.

[30] B.A. Magradze, Few-Body Systems 40, 71 (2006).

[31] G.'t Hooft, in Proceedings of the 4th International Conference on Time and Matter, editado por M. O'Loughlin et al. (University of Nova Gorica Press, Venice, 2013).

[32] R.P. Feynman e J. Robbins, Os Melhores Textos de Richard P. Feynman (Blucher, São Paulo, 2015).

[33] C.P. Snow, The two cultures (Cambridge University Press, Cambridge, 1988).

[34] B. Latour, Jamais Fomos Modernos (Editora 34, São Paulo, 2013).

[35] G. Bachelard, A Formação do Espírito Científico (Contraponto, São Paulo, 1996).

[36] B. Latour e B.S. Woolgar, A vida de laboratório: a produção dos fatos científicos (Relume Dumará, Rio de Janeiro, 1997).

[37] T. Kuhn, The Essential Tension: Selected Studies in Scientific Tradition and Change (Chicago University Press, Chicago, 1977).

[38] M. Born, Physics in my Generation: A selection of papers (Pergamon Press, London, 1956).

[39] B. Latour, Cogitamus: Seis Cartas sobre as Humanidades Científicas (Editora 34, São Paulo, 2016).

[40] D. Auler e D. Delizoicov, Ensaio 3, 1 (2001). 